\title{
THE CONFUSION OF EPISTEMOLOGY IN THE WEST AND CHRISTIAN MISSION
}

\author{
J. Andrew Kirk
}

\begin{abstract}
Summary
Western culture is facing a major intellectual crisis, because it is confused about the meaning of truth, the relationship between belief and knowledge, and the nature and use of language. This article points out some of the consequences and suggests a new way of meeting contemporary cognitive challenges to communicating Christian faith.
\end{abstract}

\section{Introduction}

The title may not seem very promising. In a quick association of ideas, epistemology and mission do not seem closely related. ${ }^{1}$ Surely, there are more important mission concerns. For example, what about the stubborn problems that arise from the process of secularisation, at the heart of which is a massive indifference to any supra-natural reality? Then again, although some writers believe we live in a post-ideological age, the all-embracing phenomenon of 'globalisation' presupposes a powerful ideology, all the more perilous for being implicit rather than overt. Ethical and cultural relativism is now assumed to such a degree,

1 To my knowledge the only published work which explicitly relates mission to epistemology is J. Andrew Kirk and Kevin Vanhoozer, To Stake a Claim: Mission and the Western Crisis of Knowledge (Maryknoll: Orbis Books, 2000). However Lesslie Newbigin, in a number of books written towards the end of his life on mission in the West, implicitly refers to some epistemological issues in his analysis and critique of the Enlightenment, for example his Truth to Tell: The Gospel as Public Truth (Grand Rapids: Eerdmans, 1991). His debt to the philosophy of Michael Polanyi is well known. Cf. also Paul Weston, 'Gospel, Mission and Culture: The Contribution of Lesslie Newbigin' in David Peterson (ed.), Witness to the World (Carlisle: Paternoster Press, 1999): 32-62; Colin Gunton, 'Knowledge and culture: towards an epistemology of the concrete' in Hugh Montefiore (ed.), The Gospel and Contemporary Culture (London: Mowbray, 1992): 84-102. 
that a putative burden of proof seems to rest on those who would dispute it. Last, but not least, the equal validity of all religious beliefs is taken for granted by most self-respecting liberal thinkers as selfevident; conversely, those who still wish to hold to the exclusive truth of their faith are dismissed as anachronistic fundamentalists.

However, interestingly, each one of these issues embodies deep epistemological premises and theories. Relativism, for example, the view that all beliefs are proportionate to particular circumstances and no belief can claim to be universally valid, because there are no generally agreed standards for ascertaining truth, only transitory and localised consensus, is a claim to knowledge about a reality open to examination. Epistemology is simply that discipline which studies the articulated or unexpressed convictions that all people have about what and how it is possible to know. As such, it deals with the assumptions that underlie any assertion that people make about any aspect of life. Though probably unrecognised by most people most of the time, its subject matter is a piece of any thinking. Action, in so far as it follows a process of self-conscious reflection, depends on epistemic principles.

The case for taking epistemology seriously as a crucial subject for mission does not have to be made a priori; it should become obvious in the course of our study. Nevertheless, we do have to establish concretely that, at present in the West, confidence in the ability to know anything is in deep trouble. We will seek to do this by showing how canons of rationality, objectivity and truth are being vigorously contested from a number of different angles. Then, we have to demonstrate that the ensuing confusion is deeply significant for Christian mission. Finally, it will be necessary to outline briefly and tentatively ways in which the Christian community might respond as a part of its given vocation to mission.

By the West I mean the shared cultural values, achievements and expectations that have developed from the history of the Western peninsular of the Asian landmass, since the flourishing of Hellenic society from the sixth century $\mathrm{BC}$ onwards. By mission I mean the process by which the Christian faith is communicated and becomes established across boundaries, whether these be geographical, cultural, ideological, linguistic, ethnic or of any other kind. The challenges, opportunities and barriers to believing and living the good news of Jesus Christ form a substantial part of the study of mission. One of its major concerns, therefore, has to be the relation between Christian 
speech and action and the different elements of culture. ${ }^{2}$ This is why students of mission have to interest themselves in other disciplines, like epistemology, even though they may not be their central concern.

\section{Epistemology as a discipline}

In its most general sense, epistemology refers to 'the theory of knowledge and justification'. ${ }^{3}$ Knowledge has been understood classically as 'justified true belief'.

Hence, the justification of beliefs is central to its concerns. Justification deals with reasons for belief, namely the evidence which is brought to bear to substantiate statements which purport to be about some reality. How does one know that something affirmed is the case? What warrants one to make truth claims?

The claim to know something is more than having justified beliefs about it, for it is possible to be justified in believing a proposition on the basis of a virtuous cognitive process and still be in error. It is normal, for example, to believe a fact on the basis of the testimony of a hitherto reliable witness, and one would be warranted in so doing. However, the witness may decide to play a practical joke (for example on the first of April) by distorting some incident or may simply, in all innocence, misinterpret some occurrence. Therefore, in order to know that fact, by removing all reasonable doubt, additional information will be necessary. In other words, knowing something is equivalent to ascertaining its status as truth.

In many ways, epistemology concerns itself with the question of the meaning of truth and the criteria that must be adopted in order to be able to distinguish true from false statements. The latter lead us on to the question of the foundations of knowledge: on what possible basis can I claim to know the truth? This issue has proved to be one of the most controversial in the history of epistemological discussion. A number of different answers have been given. ${ }^{4}$ Classically, it has

2 For further understanding of mission, cf. Roger Bowen, So I Send You: A Study Guide to Mission (London: SPCK, 1996); J. Andrew Kirk, What is Mission? Theological Explorations (London: Darton, Longman and Todd, 1999).

3 Robert Audi, Epistemology: A contemporary introduction to the theory of knowledge (London: Routledge, 1998): 1.

4 It is beyond the scope of this study to discuss all the possibilities in detail. It is, however, worth mentioning that not all views are mutually exclusive, and some people 
been asserted that reliable knowledge has to be founded on beliefs that do not themselves need justifying for they are either self-evidently true, incorrigible or immediately evident to the senses. Because of alleged difficulties in this position, known as foundationalism, other alternative theories have been put forward..$^{5}$ Thus, conventionalism argues that the basis for true statements is their concordance with the conventional uses of language, i.e. the ways in which words and signs relate to one another according to generally accepted rules. ${ }^{6}$ Coherentism, the main challenger in contemporary epistemology to the classical view, ${ }^{7}$ stipulates that what makes one belief justified and another not is the way it coheres with a particular set of background beliefs. ${ }^{8}$ Pragmatism suggests that beliefs are best justified by their practice; their truth-value is dependent on the success of their practical outcome. ${ }^{9}$ Finally, reliabilism states that a belief is justified just in case it is based on reasons that are reliable indicators of the truth, produced by cognitive processes that are generally reliable. ${ }^{10}$

\section{The nature of the present epistemological confusion}

\section{Historical antecedents}

In synthesis, the increasing uncertainty about the possibility of finding any proper basis for knowledge is due to a widespread belief that all forms of foundationalism, because of the problem of infinite regression in the chain of epistemic justifications, are inherently defective, and that all the alternatives proposed are equally, if not more, vulnerable. In

prefer to see a combination of at least some as the best possible guarantee that one can be truly justified in having certain beliefs.

5 Cf. Hugo Meynell, 'Faith, Foundationalism and Wolterstorff' in Linda Zagzebski (ed.), Rational Faith: Catholic Responses to Reformed Epistemology (Notre Dame: University of Notre Dame Press, 1993): 92-99.

6 This view has been argued most cogently by Alfred Tarski, Logic, Semantics, Metamathematics (Oxford: Clarendon Press, 1956).

7 Cf. Robert Audi, The Structure of Justification (Cambridge: CUP, 1993): 117-164.

8 This view is most closely associated with the philosophers Rescher and Bonjour, cf. Nicholas Rescher, The Coherence Theory of Truth (Oxford: OUP, 1973); Bonjour, The Structure of Empirical Knowledge (Cambridge, MA: Harvard University Press, 1985). However, in the case of Bonjour, see n. 63.

9 Cf. Richard Rorty, The Consequences of Pragmatism (Hassocks: Harvester, 1982).

10 W. J. Talbot, The Reliability of the Cognitive Mechanism (New York: Garland Publishing, 1990). 
many circles, the attempt to construct a system of knowledge on an immovable basis that is clear, universally valid and indubitable has been abandoned. It is as if one age had passed irrevocably and given rise to another whose mood is characterised by ambivalence, indecision and mistrust. ${ }^{11}$

Like all transitional situations there is a history. The birth of the modern world can be dated with some precision to the first successes in discovering how the universe functions, as these confirmed the validity of the broadly empirical procedures of the emerging sciences. For want of a better point in time we might nominate 1660, the year in which the Royal Society was founded in London. ${ }^{12}$ Epistemologically one might say that this birth was a neutral coming into being. Fundamental changes in people's ways of thinking began only when particular assumptions were linked to the scientific enterprise. Out went Aquinas, Luther and Calvin; in came Bacon, Locke and Descartes.

Bacon championed a straightforward account of the discovery of the natural world through empirical induction, in which laws and theories of science are built up out of systematic processes of observation and testing. Inductive inference is a matter of weighing the evidence, judging probabilities and drawing likely conclusions with regard to some aspect of the natural world. ${ }^{13}$ Bacon was supremely confident that the method would produce a true understanding of the Book of Nature for the immense benefit of humankind. The empirical method was further elaborated by John Locke. He espoused the view that all ideas come ultimately from experience through a process of integrating sensations, derived from the observation of external objects, and reflection, as the introspective awareness of the activities of the mind. ${ }^{14}$

Descartes, on the other hand, was aware of the sceptics' challenge to a too naïve reliance on the immediate availability of data to the human senses. Unlike the empiricist, he did not believe it possible to rely on

11 It has to be said that this mood permeates the intellectual world of philosophy, but it is not necessarily true of the scientific community nor of the business world which relies on the technological achievements of science.

12 The French Academy of Sciences followed in 1666.

13 Cf. Richard Tarnas, The Passion of the Western Mind (London: Pimlico, 1991): 275.

14 His theory of perception has been called an indirect representative realist theory because he believed that objects have the power to cause ideas in our minds, cf. A. C. Grayling (ed.), Philosophy: A Guide through the Subject (Oxford: OUP, 1995): 488508. 
the data of the senses to give unconditional knowledge. In order to stem any conceivable sceptical regress against the claims for certain knowledge, he turned inward to contemplate the operation of the mind. He sought to adduce axioms that could be seen to be self-evidently true to the faculty of intellectual intuition, as long as human rational mechanisms remained unimpaired, because they were clear, distinct and free from internal contradiction. It is possible, he reasoned, that most of what we conceive to be knowledge about the world could be undermined either by the unreliability of the senses, or by being unable to distinguish between the state of being awake or that of dreaming, or by a malicious demon who was able to deceive us into believing we had direct contact with the external world or even that the apparently cast-iron certainty of mathematical and geometrical conclusions might be false. Nevertheless, it is quite impossible to doubt that we are thinking.

His method is an attempt to overcome the lingering doubt that must always be there in the empirical method, namely that the human mind truly is in contact with real external objects. The certainty of knowledge can only be justified ultimately in the mechanisms of the reasoning subject which is able to demonstrate that doubt is selfcontradictory: the very process of doubt uncovers the existence of a thinking subject; I can only doubt by thinking, therefore I am. The intuited and incontestable axiom of the cogito is a sufficient and efficient causality for other types of knowledge. Descartes' thesis has subsequently been regarded by many commentators as the first attempt to construct a foundation for knowledge that would have immunity from error (be infallible), from refutation (be incorrigible) and from doubt (be indubitable).

Descartes' process of reflection has been called the 'rationalist turn' in Western philosophy, and it is a defining moment. In treating the notion of reality as dependent on what is clear and self-evident to the mind, Descartes has ended up in an unbridgeable dualism between mind and matter. In order to try to reconnect to the sensible world, Descartes invoked the concept of God. God is the being who brings together rational faculties and a rationally ordered world. However, for Descartes, God is a necessary postulate to overcome the ultimate limitations of reason. As such a being cannot be demonstrated by reason alone, God has to be assumed. In order not to end up in a vicious circle, it is necessary to start from a position of faith, not of 
certainty. Faith, however, cannot logically refute an unyielding scepticism. Ultimately, one has to conclude that Descartes' ingenious scheme fails on its own terms.

In the attempt to found knowledge, whether empirical or axiomatic, on the autonomous human thinking subject in direct contact with the world or the mind, the modern epistemological dilemma was born. The human subject became divorced from the external object, with the result that scepticism about the real reality of the external world has pervasively influenced all discussion about noetic procedures, and human beings have condemned themselves to various forms of solipsism. Parallel to this, in the religious sphere, there was a notable move from theism, which heralded God as the initiator of knowledge, to deism, in which God was seen as an indispensable postulate to conserve the possibility of knowledge (not least by Isaac Newton ${ }^{15}$ ), to atheism, in which the hypothesis of God was abandoned altogether. ${ }^{16}$ The consequence of this move was not only to posit naturalism as a self-sufficient account of the material world but also to erect Nature into a kind of human-transcending Subject that would perform at least some of the functions hitherto ascribed to the deity: most notably those of providing a sense of meaning to life and a foundation for morals.

An obscure philosopher from East Germany, 'aroused from his dogmatic slumbers' by the scepticism of David Hume, sought to find a secure framework in which the validity of empirical knowledge could be substantiated against the sceptics. Kant conceded to Hume the objection against empiricism that human beings cannot know the world as it is in itself $^{17}$ and the critique of rationalism that objective knowledge cannot be attained by the use of reason alone. So, Kant argued, human beings cannot know things as they are in themselves, only as they are mediated to us in experience. The raw material is given through our intuitions, which are then organised, using concepts, so

15 Cf. Michael Buckley, At the Origins of Modern Atheism (New Haven: Yale University Press, 1987): 143-144.

16 The first modern thinker openly and systematically to espouse atheism was Diderot, followed by D'Holbach and many members of his Paris circle; cf. Buckley, Origins: 194-321; Michael Hunter and David Wootton, Atheism from the Reformation to the Enlightenment (Oxford: Clarendon Press, 1992): 273-300.

17 Hume's scepticism arose from his assertion that the experience of any object was no more than an experience of its impression which, in conjunction with reflection, became a perception. Perceptions are elements or objects of the mind, not representations of external existences, cf. David F. Norton (ed.), The Cambridge Companion to Hume (Cambridge: CUP, 1993): 7-8, 107. 
that we might understand the data we experience. Knowledge is only attainable by a synthesis of sensations of objects and prior organising principles, which are the categories of the mind. The latter are innate or a priori ideas, which have to be presupposed for knowledge to be possible at all. In order to answer the dilemma of both rationalists and sceptics, such concepts can be both analytic and synthetic, i.e. both presupposed and confirmed by actual experience.

Kant's response to Hume's challenge, clever as it is, fails to overcome the dichotomy between the autonomous mind and a real world. Objects can only be known through the mechanism of an interpreting mind, as phenomena that appear to us in a certain way. The implication is that the world is actually constituted by the mind's own categories. The only world available to human consciousness is that already organised within the mind's own processes. This means that the world cannot be known in a direct sense, only thought about. Kant has come no nearer to solving the problem of bringing together an objective reality and a subjective reflection on experience. As Richard Tarnas perceptively observes, Kant had only succeeded in rejoining 'knower to known, not knower to any objective reality ... Knower and known were united, as it were, in a solipsistic prison. Man cannot know whether the internal ordering principles possess any ultimate relevance to a real world, or absolute truth outside the mind. ${ }^{18}$

Although, perhaps, intellectually the most impressive attempt to overcome the dichotomy between an assumed empirical knowledge of the natural world and a sure confidence that it is indeed knowledge, Kant not only fails to solve it but he actually makes it worse. He cannot escape from the prison of a self-referring subject to make contact with an objectively real world. He appears to have substituted the Cartesian absolute thinking subject with his own absolute experiencing subject, from which he works outward to his theory of a priori categories. However, the categories are themselves postulates of the mind necessary to make sense of experience; they are not derived from experience. They belong more to the designation noumena, the real an sich (in itself), than that of phenomena, the real as it appears to us.

The conclusion seems inevitable. As long as there is no dependable way of asserting the intrinsically absolute correspondence between a real universe and the human perception of it, human beings will be

18 Tarnas, The Passion: 348. 
trapped in what Francis Bacon called 'the idols of the cave' (individually accepted mental creations) or 'the idols of the tribe' (collectively accepted mental creations). ${ }^{19}$ The way was set for a continuing rift between the scientific enterprise, which has to assume epistemological realism in order to give an adequate explanation of its method, and yet which, in so far as it is positivistic and naturalist, has no adequate grounds for doing so, and other avenues to knowledge which appear to be trapped in an inescapable subjectivism. In the next section, we will explore how contemporary issues in epistemology follow as consequences of the split.

\section{Contemporary issues}

It is impossible to provide more than a brief summary of some of the most pressing dilemmas in the contemporary scene. ${ }^{20}$ For the purpose of this paper, I will address briefly three major questions, which I take to exhibit the main elements of the present confusion.

\section{a. The justification of beliefs}

We have already begun to discuss the various theories that have been advanced to legitimate the belief that one can know certain statements to be true. Foundationalism is the view that some beliefs are directly justified, either by being self-evidently true or immediately evident to the senses. All other beliefs are then dependent upon the foundational beliefs, as in the construction of an edifice. It has to be assumed that the regress of justified beliefs has an ultimate stopping-place, a foundational belief that it would be rationally absurd to doubt. ${ }^{21}$

However, this notion has been disputed for a number of reasons. First, the idea that facts are somehow 'given' prior to being interpreted, and that beliefs can be justified on that basis, is dismissed as impossible, since all facts are always already theory-laden. Thus, one cannot rely upon unmediated information presenting itself to the senses in such a way that the sceptics challenge to demonstrate incorrigibility can be met. Second, the infinite regress problem cannot properly be avoided, since the beliefs used to justify other claims turn out in

19 Cf. Mary Tiles and Jim Tiles, 'Idols of the Cave' in Linda Martin Alcoff, Epistemology: The Big Questions (Oxford: Blackwell, 1998): 423-424.

20 A much fuller overview is given in Kirk, To Stake a Claim: 3-52.

21 Jonathan Dancy and Ernest Sosa, A Companion to Epistemology (Oxford: Blackwell, 1992): 144-147. 
practice not to be indubitable, but dependent on the structure they are intended to justify.22 Third, there appear to be a number of contradictory theories, viewpoints and statements equally wellfounded, not all of which can be equally true. Moreover, it is alleged there is no non-arbitrary way of establishing one set of propositions as superior to another without arguing in a circle. ${ }^{23}$

The other main theory of justification is coherentism or holism. The central idea is that the justification of a belief depends on its coherence with other beliefs within a particular set. Beliefs, which are sufficient for knowledge, do not lie at the foundation of a building but make up an integrated web and their justification proceeds from being an appropriate fit within that pattern. ${ }^{24}$ For those who hold to some form of holism the theory is superior to that of foundationalism in that it allows a multi-directional flow of reasoning and different kinds of connection between beliefs. It also takes into account the observation that data are always already dependent on theoretically accepted premises. ${ }^{25}$

However, the theory is not without its severe weaknesses. Systems of belief can be fully coherent within themselves and yet be (a) incompatible with other fully coherent systems of belief, such that only one could be completely true (or, all of them false), and (b) incompatible with what is otherwise generally and universally acknowledged to be true. 'Without some independent indication that some of the beliefs within a coherent system are true, coherence in itself is no indication of truth ... Our criteria for justification must indicate to us the probable truth of our beliefs. Hence within any system of beliefs there must be some privileged class with which others must cohere to be justified.' 26

If scepticism seems to undermine foundationalism, relativism seems to be the logical outcome of holism. 'If we abandon foundationalism, we are able to defend all sorts of preposterous claims and theories by

22 Godel's theorem: 'for every sufficiently complex system of axioms and proof procedures there will always exist at least one indispensable axiom whose validity cannot be proved in terms of that same system,' C. Norris, Against Relativism: Philosophy of Science, Deconstruction and Critical Theory (Oxford: Blackwell, 1997): 22.

23 Cf. Stephen T. Davis, God, Reason and Theistic Proofs (Edinburgh: Edinburgh University Press, 1997): 91-92.

24 Audi, Epistemology: 189-190.

25 Cf. Nancey Murphy, Beyond Liberalism and Fundamentalism: How Modern and Postmodern Philosophy set the Theological Agenda (Valley Forge: Trinity Press International, 1996): 94.

26 Alan Goldman, 'The Given' in Dancy and Sosa: 160. 
showing either that they are consistent with everything else in a person's noetic structure or that beliefs tend to produce helpful practical consequences. ${ }^{27}$ It is the notion that any part of the system can be suitably adjusted in order to turn aside the challenge of defeaters that suggests an underlying disregard for any notion of truth. It would seem as if epistemic standards of confirmation are internal to the system. There may be internal coherence, but then each web of beliefs is incommensurable with every other, and there appears to be no way of judging between them.

So unconvincing do the two foremost theories of justification seem to be that a number of thinkers wish to abandon epistemology altogether. For Richard Rorty, for example, all attempts at justification are allergic and anxiety-ridden reactions to the human condition, which cannot be transcended, of necessity possessing a historically and culturally contingent view of things. The only way we can approach knowledge is on the pragmatic basis that we refine our serendipitous language and methods to cope better with life as we know it. ${ }^{28}$

\section{b. The use of language}

Following the 'rationalist turn', inaugurated by Descartes, a second major shift in epistemological theory is connected with Wittgenstein. Between the Tractatus (1922) and the Philosophical Investigations (published in 1953, two years after his death) Wittgenstein had 'taken' a 'linguistic turn.' In the first instance, he sought to lay down a uniform, logical theory of language, which fixes the bounds of meaning. He adhered to a strong picture theory in which the words in a sentence stand for objects in the world in the same way that pictures represent entities in space. Thus, 'a picture is a model of reality. In a picture objects have the elements of the picture corresponding to them. In a picture the elements of the picture are the representatives of objects ... A picture depicts reality by representing a possibility of existence and a state of affairs ... A picture agrees with reality or fails to agree; it is correct or incorrect, true or false ... The agreement or disagreement of its sense with reality constitutes its truth or falsity.' 29

27 Davis, God, Reason: 93.

28 Cf. 'Pragmatism, Relativism and Irrationalism' in Alcoff, Epistemology: 336-348.

29 Ludwig Wittgenstein, 'Picturing Reality' from Tractatus Logico-Philosophicus (London: Routledge and Kegan Paul, 1961), quoted in Andrea Nye (ed.), Philosophy of Language: The Big Questions (Oxford: Blackwell, 1998): 44-46. 
The 'first' Wittgenstein puts forward a robust representational view of language and a correspondence theory of truth. It is not surprising that his work was interpreted as providing an empiricist theory of meaning, which excluded certain categories of discourse like those of morality, aesthetics and religion. However, at a later stage, Wittgenstein became convinced that this theory of language was too restricting. The 'second' Wittgenstein developed a rule-based or ordinary-language theory of meaning. The sense of a sentence is given not so much in its depiction of an objectively accessible reality, with which it corresponds in an unequivocal manner, as in its function within the ordinary usage of a given language. One comes to know the meaning of a sentence not by grasping its relationship to some external entity but by knowing how languages work. Words obey the internal rules of 'language-games' that just happen to function in particular ways. But they can only work effectively, and solipsism be defeated, where the language-using community agrees on the rules.

This new theory of language represented a radical departure from the more positivistically inclined picture theory. More than anything else it paved the way for post-analytical and post-structuralist approaches to language which contributed to some of the perspectivist ideas characteristic of post-modernity. Language in ordinary usage is incredibly varied. Human beings cause for themselves all kinds of puzzlements when they become over-impressed or over-reliant on particular language games, most notably that of the exact sciences. However, all use of language is legitimate once its purpose is made plain in the context in which it is employed. We do not even have to find common features to link together things called by the same name: family resemblances will suffice. Wittgenstein 'conceived his task to be to remind us of what lay on the surface, not to express any opinions or offer deep explanations.' ${ }^{30}$

Hermeneutics is another major contemporary tradition in the philosophy of language, associated with the thought of Gadamer, Ricoeur, Barthes and others. Gadamer built on Heidegger's phenomenology of being. Like Wittgenstein, he moved away from associating understanding too closely with the use of language in the exact sciences. He recognised that, by privileging scientific

30 J. O. Urmson and Jonathan Ree, The Concise Encyclopedia of Western Philosophy and Philosophers (London: Routledge, 1989): 330. 
terminology as a standard for arriving at meaning, the attempt was being made to free the human subject from the contingent and circumstantial nature of being in the world. The result was the reification of nature, the attempt to stand outside history and isolate the reflecting subject from the vicissitudes of immersion in specific contexts. In contrast, Gadamer believes that understanding can only be achieved by overcoming the subject-object dichotomy through the merging of the horizons of the interpreter and the text. ${ }^{31}$ Texts always supply a surplus of meaning, not necessarily circumscribed by the author's intent. 'It is this all-encompassing horizon of language and meaning, rather than the author's intentions, which ultimately determines meaning. Language speaks through individual subjects as much as they speak through language.' 32

The recognition of the contextual nature of the pursuit of knowledge in language and past history led Gadamer to question an objectifying understanding of reason. If the reasoning person is irrevocably conditioned by his or her pre-judgements, conceptual commitments and prior intellectual frameworks, then reason may not be neatly set against tradition or even prejudice. A fresh ontology of knowing will emphasise the community dimension of understanding bounded by authority, custom and convention. Some have seen Gadamer's hermeneutical concerns as leading towards historicism with its denial of a transcendent critical perspective and its emphasis on a particularist, descriptive and contemplative method rather than a search for universal, abstract and explanatory laws of human life. Thus, he has been criticised for articulating a philosophy which could easily become compliant towards politically reactionary ideas and movements.

Contemporary moves in the philosophy of language, in an attempt to overcome the objective-subjective dichotomy, appear to have shifted decisively in the direction of the subjective. Attempts to locate understanding and meaning in the wider communal horizons of language-games and history may help to overcome individualism but give no necessary escape from subjectivism. This is born out in the post-structuralist development towards the 'deconstruction of linguistics'. Roland Barthes is a representative of the view that

31 Text is to be understood as a reference to 'all fields of human life and inquiry', Kirk, To Stake a Claim: 10.

32 David West, An Introduction to Continental Philosophy (Cambridge: Polity Press, 1996): 112. 
language has to be liberated from all fixed meanings. He believes that literature is a privileged medium of revolt, 'because it enables us to experience words not as simple instruments (as the scientific attitude dictates) but as ... an infinitely playful performance of signification to be hedonistically savoured in all its pluri-dimensional richness. Literature, in short, reconverts knowledge into desire.' 33

\section{c. Questions of truth}

If it is evident that one cannot know any fact or statement of belief unless one is assured of its truth-value, then apprehension of the truth becomes the most fundamental issue in epistemology. However, the very notion of truth has come under attack from two principal quarters. First, the definition of truth as 'conformity with what is' has been disputed by different kinds of anti-realism. According to this latter view, verification of the truth of a statement about the real world is not possible, since the real world is not directly accessible to us. Contact with anything deemed in some way to be independent of us has to be mediated by thought-processes, using language, that are always already shaped by currently accepted theories and procedures.

There are a number of variations of this position. A game-theory approach states that truth is a matter of linguistic or discursive convention within a community. It is arrived at by a process of negotiation between two or more apparently incompatible representations of reality. ${ }^{34}$ A Kuhnian theory of paradigm shifts in science affirms that scientific conclusions are always underdetermined by data and that, therefore, their 'truth' can be little more than their general acceptability within the scientific community. The choice to believe, he argues, is determined to a large extent by prevailing paradigms, rather than by strictly evaluated evidence conforming to an objective state of affairs: 'Objectivity consists, not in the correspondence of our theories to the world, but in the inter-subjective agreement about those theories among members of the scientific community based on their shared values. Kuhn identifies objectivity and rationality with a special sort of consensus, a consensus based on the values that make science what it

33 Richard Kearney, Modern Movements in European Philosophy (Manchester: Manchester University Press, 1994): 330.

34 Cf. Christopher Norris, Reclaiming Truth: Contribution to a Critique of Cultural Relativism (London: Lawrence and Wishart, 1996): 35-39. 
is. ${ }^{35}$ A strong version of the sociology of science argues that the measure of true belief and rationality is determined by particular historical circumstances. ${ }^{36}$ Criteria for the justification of scientific explanations are inescapably tied to the conditions of their discovery: 'What counts as scientific 'truth' - so the authors maintain ${ }^{37}$ - is determined neither by the ways things stand in reality, nor by any special merit - any 'inherent' truth-related virtue - in those theories or procedures that happen to gain widespread communal assent. Rather, it is a product of the reception history (or the cultural pressures making for acceptance or rejection) to which all truth-claims are constantly exposed and which thus provide the ultimate court of appeal in matters of scientific 'fact'. ${ }^{38}$

Secondly, truth is said to be linked to structures of power in society. "Knowledge" and "truth" are compliments paid to successful discourse, as Rorty and others have suggested'. ${ }^{39}$ By this is meant a definition in terms of that sector of society that has managed to have its views accepted. Derrida, for example, seeks to undo the binary division in the history of philosophy in which, among other opposites, truth has been privileged over error. The problem with this way of thinking, he argues, is that it exalts a hierarchical model for knowledge which excludes difference and 'the other.' Thus truth becomes a repressive reality, a notion explored at some depth by Michel Foucault in his critique of the historical development of certain social institutions. Truth becomes assimilated to the consensus of the experts, whose thought is always already expressive of some prior political or ideological commitment. ${ }^{40}$

The strong critique of the classical concept of truth, ${ }^{41}$ with its emphasis on correspondence, the logic of antithesis and the excluded

35 Martin Curd and J. A. Cover, Philosophy of Science: The Central Issues (New York: W. W. Norton, 1998): 227.

36 Cf. Mary Hesse, Revolutions and Reconstructions in the Philosophy of Science (Brighton: Harvester Press, 1980): 31-33.

37 Shapin and Schaffer, Leviathan and the Air-Pump: Hobbes, Boyle and the Experimental Life (Princeton: Princeton University Press, 1985).

38 Norris, Against Relativism: 271.

39 Bernd Magnus and Kathleen Higgins (ed.), The Cambridge Companion to Nietzsche (Cambridge: CUP, 1996): 6.

40 Cf. Alan D. Schrift, 'Nietzsche's French legacy' in Magnus, Companion to Nietzsche: $338-340$.

41 William Alston, A Realist Conception of Truth (Ithaca: Cornell University Press, 1996), provides a robust response to the prolonged and fierce attack on the traditional 
middle, a representative account of language and a robust realism, has given rise to a number of alternative theories. ${ }^{42}$ In differing degrees each one presupposes an internal perspective from which criteria for truth can be elaborated. In reality, they are much more about clarifying the standards for measuring truth-claims than about the definition of truth itself. Thus, a pragmatic version highlights functionality as the primary criterion: beliefs that bring about desirable results are said to be truth-indicative. The performative theory, which maintains that truth-claims are veiled devices for asserting assent or dissent to propositions, is merely a way of describing a mechanism. Jurgen Habermas' consensus theory, which proposes that a truth-claim is an affirmation of validity whose legitimacy can be tested in an 'ideal speech situation' (i.e. one in which all communication is completely free from ambivalence and misrepresentation) is a way of stipulating the conditions necessary for a claim to truth to be justified. Understood as means for distinguishing between truth and error, some of these theories have merit. However, the correspondence theory is the only one that deals with the nature of truth as such. Hence, it is the one that is most attacked by all those who wish to discredit the notion of truth altogether.

\section{The missiological significance of the epistemological confusion}

In a presentation of this nature there is always the risk of oversimplifying highly complex issues. For this reason, both the descriptive and analytical parts of this discussion will remain tentative and unfinished. However, the mission of the Christian community cannot remain static until and unless we are able to produce a near-perfect evaluation of contemporary culture. It is possible, I believe, to describe in a competent and fair way the main problems in the modern Western tradition of believing and knowing. It is also possible to deduce from this exploration some key conclusions, which become the context for mission, without ever having to produce an exhaustive and faultless account of the subject.

view. Nicholas Wolterstorff comments on the book: 'the common dismissal of the correspondence theory of truth as outmoded has itself become outmoded.'

42 They are set out in Kirk, To Stake a Claim: 30-34. 
Our survey has concentrated on two pivotal and momentous radical breaks in epistemology in the West, which have become defining moments for the whole of subsequent thought. The first can be described as the shift from an integrated concept of knowledge, in which confidence in the trustworthiness of the Book of God as a true account of the place of humanity in the universe was balanced by confidence in the ability of human beings to discover the Works of God, to a disintegrated account of knowledge in which the first strand was discredited and the second strand was exalted into the sole source of understanding. The result has been a clear division between knowledge revealed by the initiative of God and knowledge acquired through the enterprise of human reason without reference to God. ${ }^{43}$ The second shift has been marked by the belief that all ideas in the fields of language, history and culture (and in some cases even science) are conditioned by and relative to particular perspectives. Previous claims to universal and absolute knowledge about the origin, nature and destiny of the universe and humanity are deconstructed into so many different and often incommensurable angles, stances and interpretations, none of which could assert any superior access to a (nonexistent) category called truth. ${ }^{44}$

The first shift could be described as a transition from a pre-modern view of reality, based on a committed and yet modest scientific outlook, still reverent towards the author of the natural world, to modernity as a view that the natural world is all the reality there is. The second shift denotes a transition to what might be called countermodernity (not post-modernity, for that suggests the beginning of another creative stage of human intellectual endeavour, whereas the situation is one of dissolution and dispersal). The consequences of each shift have been immense. The general result is that many wish to abandon epistemology altogether as the search for justified true beliefs, replacing it with a thorough-going and enervating suspicion towards all norms, codes and the truth-regulating theories that support them and the exaltation of polycentric suppositions about the meaning and conduct of life.

43 It was not long before Nature supplanted creation as a description of the material world.

44 The discussion that follows is developed at much greater length in a forthcoming book, J. Andrew Kirk, Following Modernity and Post-Modernity: In Pursuit of Another World. 
It would be easy to write the history of the West over the last half millennium as if it were an uninterrupted progression from pre-modern ideas to those of modernity and counter-modernity, such that it appears predetermined and irreversible. If such an account were the only one available, the present dichotomy between knowledge of the objective world outside and the subjective inner world would be prolonged and become established. Then humanity would be condemned to a totally fruitless search for an intrinsically unavailable, integrated understanding of the whole of reality. Then the story of Sisyphus would seem a good way of describing the utter frustration of a generation endued with enormous technical information, intellectual power and rational ingenuity but unable to solve the most fundamental questions of existence.

For the time being, the epistemological dilemma of the West remains unresolved and irresolvable, for the intellectual tools deemed by the majority to be the only ones available are inherently incapable of 'putting Humpty-Dumpty together again.' The failure to bring together the assumptions about reality necessary for the scientific enterprise to be possible ${ }^{45}$ with a comprehensive explanation of human beings' experience of being human is the context for mission in the West. Prior to thinking about missiological responses, we need to feel deeply the effects of the situation we are part of.

Contemporary mainstream thought in the West assumes a naturalistic interpretation of life. Some form of evolution of all species from a common beginning through mutation, natural selection and the survival of the fittest is taken for granted as the explanation for life on earth. Modern rationality has deemed intelligent design either impossible or implausible, so that the universe as we know it is the result of blind chance (through the replication of selfish genes) and has no explanation beyond the bare fact of being what it is. ${ }^{46}$ The consequence of naturalism is that we can do no more than accept the way things appear to be and endeavour to understand how they function: beyond an empiricist account of the observable world everything is speculation.

45 Roger Trigg argues effectively that science cannot find within its own assumptions those necessary for its conclusions to be validated; its methods are predicated on premises that cannot be corroborated by these methods. Cf. Rationality and Science: Can Science Explain Everything? (Oxford: Blackwell, 1993).

46 According to Richard Dawkins, 'Bernard Shaw said that when you contemplate Darwinism your heart sinks into a heap of sand within you,' Andrew Pyle (ed.), Key Philosophers in Conversation: The Cogito Interviews (London: Routledge, 1999): 73. 
Needless to say, within this perspective the uniquely human notions of purpose, beauty, conscience, consciousness, language and imagination cannot be elucidated. This prompts a number of writers to produce what can only be called a 'projection theory' of moral and aesthetic judgement: even though neither has any objective existence, we have created both in order that we might live more humanly. We can only live as if they reflected a reality independent of our subjective musings. ${ }^{47}$

Such an outcome of a consistently naturalist view of life, when compared with the projection theory of the existence of God, is a fascinating case of et tu, Brutus! As we have no rational means of escaping from the imprisonment of our own cogito, in order to account for the foundations of life that are necessary for us to flourish properly as human beings, we have to fabricate illusions. It is hard to imagine a more devastating critique of the inadequacies of rationalism and empiricism than this attempt to invent a reality in order to escape from the possibility that nothing is real. ${ }^{48}$

The post-modern breakdown of the rationalist/empiricist consensus leads to a further dimension of unreality. In one sense, post-modern consciousness utilises the Hegelian method of the negation of the negation. ${ }^{49}$ The original negation practised by modernity, was, as we

47 Cf. the attempt by Mary Midgley to give a coherent account of the origin of ethics from within a naturalistic evolutionary framework in 'The Origin of Ethics' in A Companion to Ethics, ed. Peter Singer (Oxford: Blackwell, 1993): 3-13. Michael Ruse, 'The Significance of Evolution' in Singer, Companion: 500-510, is honest, though also extremely cynical, in his evaluation of the place of ethics in an evolved world: 'Morality remains without foundation ... Why does such a thesis ... seem so intuitively implausible? Why does it seem ... so ridiculous to argue that morality is no more than an illusion of the genes? ... The simple fact is that if we recognised morality to be no more than an epiphenomenon of our biology, we would cease to believe in it and stop acting upon it ... What this means is that, even though morality may not be objective in the sense of referring to something 'out there', it is an important part of our experience of morality that we think it is' (pp. 507-508). Anthony O'Hear, Beyond Evolution: Human Nature and the Limits of the Evolutionary Explanation (Oxford: Clarendon Press, 1997), on the other hand, concludes that 'Darwinism, if applied to our forms of intellectual, moral and aesthetic life, is indeed a dangerous idea' (p. 214). Yet with regard to aesthetics he says, 'Aesthetic experience seems to produce the harmony between us and the world that would have to point to a religious resolution were it not to be an illusion. But such a resolution is intellectually unsustainable, so aesthetic experience, however powerful, remains subjective and, in its full articulation, illusory' (p. 201).

48 For an extended critique of naturalism as a self-refuting theory, cf. Rationality and Science: 80-92.

49 Cf. T. Bottomore, A Dictionary of Marxist Thought (Oxford: Blackwell, 1991): 400. 
have seen, the refusal to countenance any source of knowledge beyond the empirical or the axiomatic. The second negation is tantamount to a repudiation of knowledge as justified true belief. Truth is regarded by post-modern thought as a mistaken category for it appears always to assimilate all differences to the same, thus violating the minority voice and exotic conduct. Truth-claims ignore the contextuality of all perspectives: the impossibility of stepping outside nature, history or culture means that all assertions are merely one of many interpretations of multi-faceted existence from an incontestably relative viewpoint. Thus, the principle that all non-empirical claims to know can only have the status of opinions is now extended to all claims. The 'text' is no longer authoritative in the sense that the reader 'is given' a univocal exposition of its purport. The meaning is not to be sought 'behind' the text, in the intention of the author (in the case of the Book of Nature, God), but 'before' the text in an endless signification made possible by the fantasy of human imagination. ${ }^{50}$

An attentive reading of the contemporary state of epistemology, as a result of the changes and disputes of the past three hundred years, will show that it presents a number of immense challenges to the thinking and practice of Christian mission. First, we might note the difficulty of proclaiming what purports to be the word of God in a world that distrusts words because of the way they have been used to create oppressive ideologies and manipulate beliefs. Christian preaching has to overcome the near instantaneous suspicion that its affirmations are mere propaganda. Related to this, secondly, is the observation that, if God has spoken, his communication is only available in the timebound, humanly fallible medium of linguistic expression open to multiple interpretations. Moreover, to accept that only one particular ethnos is the privileged recipient of this communication is gratuitously 'racist' in a world made aware of the positive value of multiethnicity. ${ }^{51}$

Thirdly, the task of making sense of a divine reality in an age that has 'taken leave of God' is massive. The present age is scarcely

50 Commenting on Derrida's method, Anthony Thiselton says, 'Meaning is always postponed, in the sense that new meanings constantly overtake it as new interests and new cultural frames repeatedly change its multi-level currencies', Interpreting God and the Postmodern Self: On Meaning, Manipulation and Promise (Edinburgh: T\&T Clark, 1995): 15.

51 Cf. Philip Clayton, 'Missiology between Monologue and Cacophany' in Kirk, To Stake a Claim: 80. 
interested in debating the possibility of the existence of God. So, it may be futile for Christians even to begin to deal with objections to classical theistic proofs, or with sceptical arguments based on the problem of evil, or with the supposedly egalitarian notion that truth resides somehow in all religions, or with the dismissive pronouncement that God is no longer an indispensable hypothesis for morality or personal meaning. ${ }^{52}$ The legacy we have inherited from Nietzsche is that God is not just improbable but incredible. The 'death' of God does not arise from the normal atheistic refusal of theistic demonstration, but is the consequence of the shattering of all illusions and the disappearance of all fixed points. If modernity brought the 'disenchantment of the world', Nietzsche has brought its elimination in the form conceived by the Hebrew-Hellenistic synthesis. His thought gives rise to the 'birth of tragedy' alongside the self-confidence of scientific humanism. He begins to exalt the Dionysian principle of 'frenzy, excess and the collapse of boundaries' over the Apollonian principle of 'order, static beauty and clear boundaries. ${ }^{53}$ For if God is no more, then there can be (and must be) a transmutation of all values. It is not surprising, perhaps, that the apparently confident proclamation that God is dead was actually made by a madman. ${ }^{54}$ Nietzsche adds the ironic comment that the scientific atheists who heard the announcement merely laughed and mocked.

Following on from the 'assassination' of God comes the death of self. In his Twilight of the Idols, Nietzsche affirms that 'We have done away with the true world: what world is left over? The apparent one, maybe? ... But no! Along with the true world, we have done away with the apparent!' Ian Markam comments, 'Nietzsche understood completely that everything is at stake once one understands that theism is false. ${ }^{55}$ But this is an absolutely logical conclusion, once the search for

52 Nevertheless, Ian Markham, Truth and the Reality of God: An Essay in Natural Theology (Edinburgh: T\&T Clark, 1998), argues enterprisingly that justified rationality depends on the existence of God. Using a mode of argument that I shall endorse myself later, he contends that refusal to acknowledge an intelligent creator leaves all other traditions either incomplete, for not having uncovered properly their epistemological assumptions, or incoherent.

53 Cf. Magnus, Companion to Nietzsche: 22.

54 The Gay Science, translated by Walter Kaufmann (New York: Vintage, 1974): part III, section 125 .

55 Truth and the Reality of God: 115. The madman finishes with the words, 'Must we ourselves not become gods simply to appear worthy of it? There has never been a greater deed ...' 
a stable account of reality is undermined by the constantly subjective perspective from which all things are viewed. Christian mission in the West can only be undertaken now in the context of the death of God, the metamorphosis of all values and the loss of the centre of being. In the dialectical march of history (or, as Nietzsche would affirm, its eternal recurrence), the Apollonian principle of system and organisation in the 'globalised' world economic and political order is in tension (or conflict) with the Dionysian principle of individual hedonistic self-gratification. ${ }^{56}$

\section{Engaging the predicament missiologically}

If the above account is anything like accurate, what response can be given from within a Christian account of life? Assuming that it is illegitimate either to reject all the main cultural paradigms out of hand, attempt to withdraw into a fideistic self-referring world, ${ }^{57}$ or to adapt the Christian faith wholesale to contemporary forms of believing and acting, what is the way forward? My belief is that Christians have to work at producing a more convincing epistemological model than the ones on offer today. My view is that this can only be done by retrieving an account of knowledge which brings together once again the Word of God and the Works of God into a consistent explanation of the whole of reality.

For such an enterprise to be credible as a mission strategy for the Christian community in the West, it will be necessary first to overcome a whole series of intellectual prejudices against faith as an epistemic requirement for any worthwhile knowledge to be possible. ${ }^{58}$ Secondly,

56 Powerfully portrayed by Zygmunt Bauman in Work, Consumerism and the New Poor (Buckingham: Open University Press, 1998). His comment that consumers are guided by aesthetic interests rather than ethical norms (p. 31) echoes Nietzsche.

57 By fideism I understand an epistemic stance in which fundamental Christian beliefs are deemed to have their own self-confirming justification and other sets of beliefs are considered largely incommensurable. It is not of consequence to fideists that their beliefs do not relate directly to a universal epistemic discourse, for knowing is said to depend on the adoption of a prior faith commitment which has its own warrant.

58 Cf. Juan Luis Segundo, Faith and Ideologies (London: Sheed and Ward, 1984), calls it 'anthropological faith', meaning the mechanism by which human beings place in hierarchical order their values, arriving ultimately at one to which they subordinate all the rest (cf. p. 25). Knowledge is dependent on a prior acceptance that reality exists in a particular way: to attempt a purely empirical description begs several questions, and involves circular reasoning. In this sense, ontology precedes epistemology, and Descartes' famous aphorism is reversed: I am, therefore I think. Our only access to the 
it will be necessary to establish that there is no other way of overcoming the damaging rift between subject and object, which is the most notable outcome of modern cognitive assumptions, and thus restoring humanity once again to its proper place in the cosmos.

This will entail an immense intellectual effort, for the mood of the West is not conducive to listening to what many now consider to be an alien voice - can anything good come out of Nazareth? There is almost a prior task to be done of persuading Western men and women that Christianity does not belong only to the past. This is not solely, nor primarily, a research project but a commitment by the community to more consistent and percipient ways of living the Gospel in an inevitably alien territory, so that the discipleship principles of Jesus may be seen to be more productive of authentic human life than those of either Apollo or Dionysus.

However, the intellectual task is also a vital part of contemporary Christian mission. Christian theology, in so far as it accepts a missiological responsibility, will necessarily have to engage in the discourse of apologetics, meaning by this both dialogue and testimony, both genuine listening and speaking. It will need to seek out the appropriate contemporary equivalents of the market-place and the Areopagus (Acts 17:17,19), in order to test out its claims in the current global supermarket of beliefs. Against the prevailing trend it will resolutely and boldly, but non-aggressively, present its conviction that the Gospel gives the only comprehensively true interpretation of life, and that therefore all others are to a greater or lesser extent defective. It will expect that its views will be contested, for both rational and nonrational reasons, for according to its own message the human intellect is constantly affected by choices, made by the will, which subvert attempts to produce a comprehensive rationality. A perverted will is always likely to defend cognitively incoherent positions. ${ }^{59}$

ultimate nature of reality is through belief that it is such and such. However, in distinction from 'fideism', belief has to be credibly based on evidence and virtuous reasoning practices: it is not indiscriminate faith.

59 More theological reflection needs to be done on the effects of sin on human reasoning. Unfortunately, there is still a divide between Catholic and Reformed positions, which became entrenched in a polemical atmosphere. Perhaps, there is some hope of closer agreement in the current willingness to discuss differences, cf. Linda Zagzebski, 'Religious Knowledge and the Virtues of the Mind' in Zagzebski, Rational Faith: 206-207. 
My own research and thinking has caused me to believe that one of the most fruitful approaches to the epistemological predicament of the West is to adopt the heuristic method known as 'inference to the best explanation.' This states that, given a particular piece of evidence (E) and several different hypotheses $(\mathrm{H}, \mathrm{H} 1, \mathrm{H} 2$, etc.) designed to give an explanation of $\mathrm{E}$, we should infer $\mathrm{H}$ rather than the alternatives if it provides the most convincing explanation of the phenomenon E. ${ }^{60}$ As a missiological project, this means that Christians argue for the truth of the Christian faith on the basis that, of all possible explanations of our experience of the universe, whether religious or secular, it gives the most comprehensive and consistent account. Michael Banner, who expounds the approach in some detail, states that a theory's explanatory power is measured by observational success in accounting for known data and in suggesting new and corroborated observations. It has greater explanatory success over a wider range of phenomena than any of its rivals and can even account for all alternative explanations. ${ }^{61}$ The advantage of adopting this model is that one has to take seriously both universally available evidence and proven categories of rational argument. This means that the explanations put forward are not private and esoteric intuitions or intimate, personal mysteries. Thus, truthclaims are related to experience of the world, self-awareness, universal concourse of traditions and ideas in an open exchange of views.

In terms of the discussion of epistemology, the following elements seem to be implied. In the first place, a moderate foundationalism, supported by a robust realism, ${ }^{62}$ is essential to provide a coherent framework for the theory to function properly. The foundation is that the existence of the God revealed in Jesus Christ affords the best possible explanation for the whole of reality as we experience it. ${ }^{63}$ It is

60 Cf. Lipton, Inference to the Best Explanation (London: Routledge, 1991); Curd, Philosophy of Science: 1075-76; The Blackwell guide to epistemology, ed. John Greco and Ernest Sosa (Malden, Mass.: Blackwell, 1999): 48-49, 77-78.

61 Michael Banner, The Justification of Science and the Rationality of Religious Belief (Oxford: Clarendon, 1990): 132.

62 There is not space to discuss adequately the concept of critical realism as an approach to knowing. I agree broadly with Roger Trigg's hesitations about the way the idea is used in both science and theology, cf. Rationality and Religion: Does Faith Need Reason? (Oxford: Blackwell, 1998): 84-87. The concept sounds modest, selfcritical and self-correcting. However, as often employed, it is ambiguous and ultimately not very resistant to a creeping scepticism.

63 The conclusion has to be that foundationalism, carefully defined, has not been defeated by its alleged problems. It is surprising, in the light of the vigorous defence of some form of foundationalism by leading contemporary philosophers (e.g. Audi, 
foundational in the sense that it is basic and, as a premise, does not need further beliefs to justify it. It is moderate, in being fallibilist: that is open to refutation, not being immediately self-evident or immune from the need to provide reasons in open debate.

In the second place, the method is both faith-explicit and yet not enclosed in its own web of tradition. ${ }^{64}$ Very specifically, it claims to be commensurable with other possible hypotheses, explanatory of some of the evidence, in that it is rationally consistent and evidentialist. ${ }^{65}$

Structure of Justification; Roderick M. Chisholm, 'The Myth of the Given' in Epistemology: An Anthology, ed. Ernest Sosa and Jaegwon Kim [Malden, Mass.: Blackwell Publishers, 2000]: 107-119) that some theologians can speak so confidently of living in a post-foundationalist age, cf. Murphy, Beyond Liberalism, and J. Wentzel van Huyssteen, Essays in Postfoundationalist Theology (Grand Rapids: Eerdmans, 1997). I wonder, for example, whether it has escaped their notice that Laurence Bonjour, once a doughty critic of foundationalism and defender of coherentism, has recently switched sides, cf. his 'Can Empirical Knowledge have a Foundation?' in American Philosophical Quarterly 15.1 (1978): 1-13; 'The Elements of Coherentism' in Alcoff, Epistemology: 210-231, where he defends coherentism, and 'The Dialectic of Foundationalism and Coherentism' in The Blackwell Guide to Epistemology, ed. John Greco and Ernest Sosa (Malden, Mass.: Blackwell, 1999): 117-142, where he says, "my conclusion for the moment is twofold: (1) coherentism is pretty obviously untenable, indeed hopeless; and (2) a very traditional version of experiential foundationalism can be successfully defended against the most immediate and telling objection' (p. 139). He elaborates his revised position in a technical study, In Defense of Pure Reason (Cambridge: CUP, 1998), passim.

64 It is not possible to discuss here whether it is compatible with Susan Haack's 'foundherentism', cf. her Manifesto of a Passionate Moderate (Chicago: University of Chicago Press, 1998): 85-86, 143-144, Polanyi's theory of personal knowing and tacit believing or Linda Zagzebski's virtue epistemology, cf. 'Virtues of the Mind' in Sosa and Kim: 457-467. However, I suspect that what differences there are may not be crucial. It is not, however, congruent with the 'Reformed' epistemology of Plantinga, Wolterstorff and Mavrodes which appears to reject foundationalisms of all colours and replaces them with an epistemology of properly warranted basic beliefs and cognitive proper functioning, cf. Plantinga, 'Warrant: A First Approximation' in Sosa and Kim: 445-456, Nicholas Wolterstorff, 'Epistemology of Religion' in Greco and Sosa: 312317. There is not space to discuss adequately this account of epistemic validity. Suffice to say, that, in my opinion, Reformed epistemology substitutes the notion of 'entitlement' for that of justification, because of its fear of the Lockean, Enlightenement form of evidentialism, which makes belief in God dependent on more fundamental beliefs. In this sense, the notion of warrant is actually anti-foundationalist. My position is foundationalist, in acknowledging the necessity of evidence, but moderate, in seeing evidence as a tool not a master. There is room for the further clarification of the use of hotly disputed terminology: for an extended review of Reformed epistemology, cf. Trigg, Rationality and Religion: 113-132.

65 Evidentialism is the view that a belief is justified if and only if there is sufficient evidence for it. Evidence may be interpreted widely, as would be the case in a legal judgement, coming in the form of eye-witness testimony, reliable memory, sense perception, other beliefs, supporting statements and integrity of character. The analogy with the procedures of a law-court is illuminating in that, in order to be creditable, evidence must be able to withstand rigorous cross-questioning. Sufficient evidence is 
Therefore, in principle, there are criteria held in common for deciding between competing explanations. In the last analysis, a Christian moderate foundationalism would claim that not all alternatives are either equally consistent internally or able to give as comprehensive a clarification of reality in its widest extension. Here, it is necessary to clarify that evidence is not used in the model to justify a foundational belief, but to supply supporting testimony; otherwise, evidentialism could be taken as contradicting foundationalism.

In the third place, it is able to do justice epistemically to both a common-sense account of knowing and the most sophisticated scientific theories. We touch reality because it is there in ordinary everyday experience and in the work of scientific discovery. ${ }^{66}$ It is there because it was put there in the act of personal divine creation and re-creation. We also know it is there because of the consequences of denying its reality.

Fourthly and finally, it brings together belief and action in the process of establishing the truth. Kevin Vanhoozer has developed an epistemology in a Christian perspective which combines testimony, interpretation and endurance as a means of demonstrating, not only the intellectual advantage that a Christian account of the universe holds, but also the pre-eminence of Christian living as a witness to the consistency possible between belief-systems and practice. In a presentation on epistemology in a missiological context his words ring true:

The vocation of the Christian theologian is to be an interpreter-martyr: a truthteller, a truth-doer, a truth-sufferer. Truth requires evangelical passion, not postmodern passivity; personal appropriation, not calculation. The theologian embodies in his or her own person the core of Christian culture, in order to provide a focus for Christian wisdom. Making Christian truth claims ultimately is not a crusade, nor a pilgrimage, nor even a missionary journey, but rather a martyrological act. Genuine theology is not only about the art of reasoning well (rationality), but about living well (wisdom) and dying well (martyrdom). ${ }^{67}$

that which satisfies 'all reasonable doubt'. Evidentialism rules out any approach to knowledge that relies on the self-justification of beliefs.

66 The combination of the two is attested by a remark, attributed to Richard Dawkins, that he did not know anyone who would not be a realist flying at 30,000 feet! Cf. Christopher Norris, 'But will it fly? Aerodynamics as a Test Case for Anti-Realism' in Norris, Against Relativism: 248ff.

67 'The Trials of Truth: Mission, Martyrdom, and the Epistemology of the Cross' in Kirk, To Stake a Claim: 156. This vocation is, of course, required of all Christians, not just those formally trained in the theological disciplines. 